\title{
Treatment of Chronic Hepatitis C: Efficacy, Side Effects and Complications
}

\author{
Lisa Sandmann Benjamin Schulte Michael P. Manns Benjamin Maasoumy \\ Department of Gastroenterology, Hepatology and Endocrinology, Hannover Medical School, Hannover, Germany
}

Keywords

Hepatitis C virus · Antiviral therapy · Treatment · Side effects $\cdot$ Complications

\section{Abstract}

Background: Chronic hepatitis C virus (HCV) infection can lead to liver cirrhosis and its complications. Viral eradication is essential to prevent disease progression and reduces liverrelated mortality and morbidity. Since the availability of direct-acting antivirals (DAA), HCV treatment has changed significantly. Current treatment strategies for different groups of patients as well as potential risks and caveats will be discussed in this review. Summary: Interferon-free (IFN-free) treatment not only shortens treatment duration, but also achieves high rates of viral clearance and is overall well tolerated. Genotype-restricted but also pangenotypic combinations are available. Usually two DAA of different drug classes are combined. For the majority of the patients, treatment duration ranges from 8 to 12 weeks. Liver and kidney function as well as prior treatment experience and potential drug-drug interactions influence substance choices and treatment duration. However, modern IFN-free treatment is not only safer, but also overall far more simplified and effective. Global HCV eradication might be an ambitious but not completely unrealistic goal to pursue. Key Messages: IFNfree antiviral treatment is safe and well tolerated. Patients can be treated almost independently of liver function or concomitant disease. Viral eradication is associated with reduced morbidity and mortality and better quality of life.

\footnotetext{
(c) 2019 S. Karger AG, Basel
}

(C) 2019 S. Karger AG, Basel

\section{Introduction}

With approximately 71 million people infected worldwide, hepatitis $\mathrm{C}$ virus (HCV) infection is a major global health concern. Chronic infection can lead to liver cirrhosis, hepatic decompensation and/or hepatocellular carcinoma which are associated with high morbidity and mortality $[1,2]$. In addition, HCV can be associated with relevant extrahepatic manifestations like hematoproliferative disorders and has recently been identified as a risk factor for cardiovascular diseases. The main objective of antiviral treatment is the reduction of these complications by achieving complete viral eradication defined as undetectable HCV RNA 12 weeks after the end of antiviral treatment (sustained virological response, SVR) [3]. Even in patients who already developed advanced liver fibrosis, a normal life expectancy can be achieved by viral eradication as it has been shown by data derived from interferon (IFN)-based therapies [4]. Of note, it has been shown that SVR not only reduces liver-related morbidity and mortality, but also improves health-related quality of life [5-8]. Since the availability of direct-acting antivirals (DAA), HCV therapy has been revolutionized. Compared to former IFN-based regimens DAA treatment is highly effective in the majority of the patients. Therapy is not only shorter, but also well tolerated and even most patients with former contraindications to IFN therapy, mainly patients with decompensated cirrhosis or significant comorbidities, can now be treated. Despite the overall success, antiviral treatment of certain groups of patients remains challenging. Even if severe side effects are 


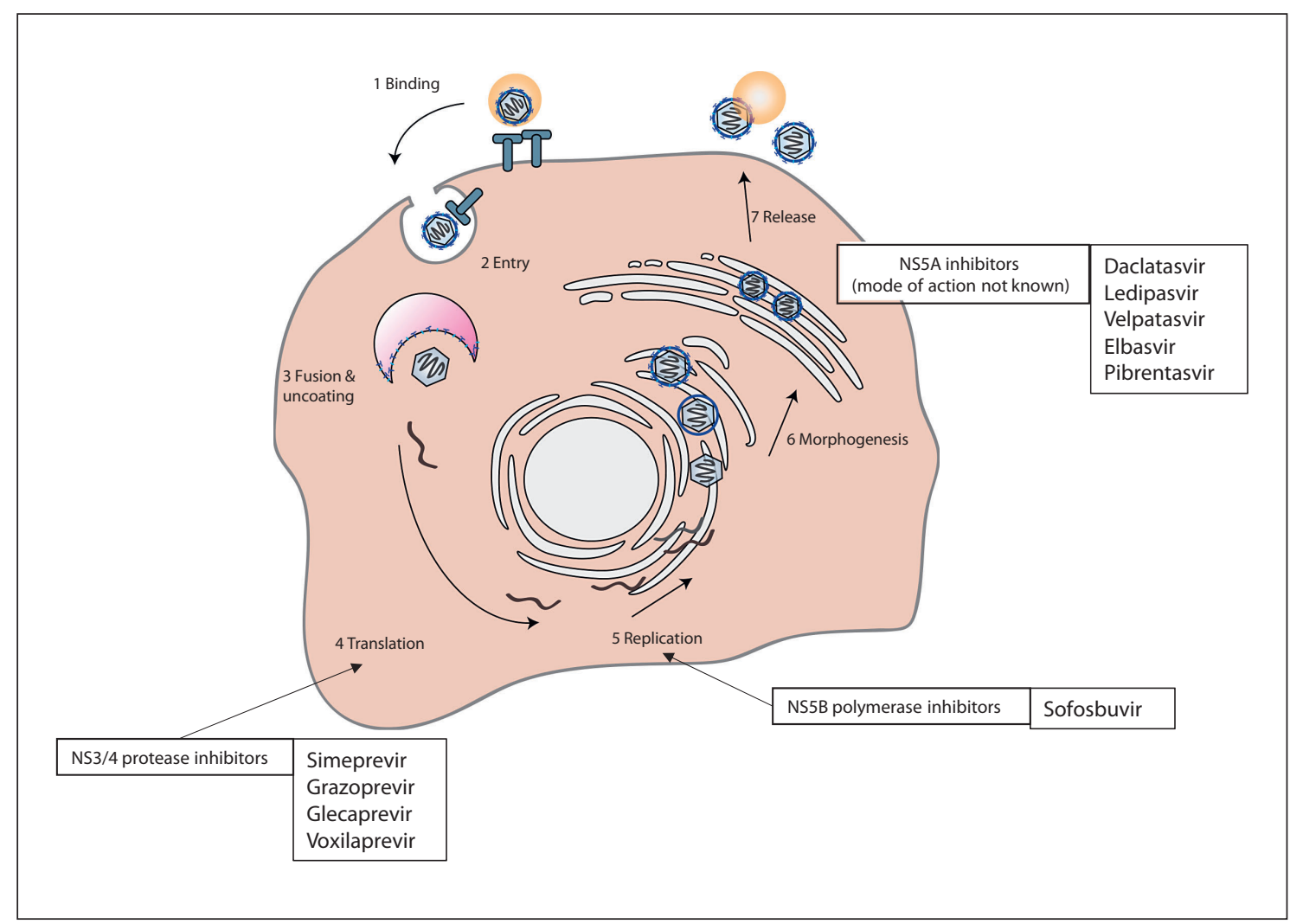

Fig. 1. The replication cycle of the hepatitis $C$ virus and modes of action of direct-acting antivirals are displayed (adapted from Manns and Cornberg [69] and Mauss et al. [70]).

rare, they are not completely absent especially in patients with advanced liver disease in whom the usage of ribavirin $(\mathrm{RBV})$ is still recommended $[3,9,10]$. Furthermore, the possibility of drug-drug interactions (DDI) is of special concern since nowadays patients with severer comorbidities might be treated due to overall good tolerability of DAA treatment [11-13]. And last but not least, a minority of patients fails DAA treatment and is in need of second-line antiviral therapy for which resistance-associated substitutes (RAS) may sometimes need to be considered.

In this review we will discuss the current antiviral treatment strategies and elucidate remaining challenges and caveats during DAA therapy.

\section{Current Antiviral Treatment Strategies}

The introduction of DAA revolutionized the field of antiviral therapy for patients chronically infected with HCV. Antiviral therapy usually consists of at least two antiviral substances from different drug classes with different modes of action (Fig. 1). Treatment decisions are based on (sub-)genotype (GT), presence of cirrhosis and response to prior treatments [3]. Typical treatment regimens for patients with and without compensated cirrhosis are depicted in Tables 1 and 2. All different recommended regimens achieve SVR rates of more than $95 \%$ if administered correctly [3].

The pangenotypic drug combinations sofosbuvir/velpatasvir and glecaprevir/pibrentasvir show high antiviral efficacy against all HCV genotypes. Treatment duration differs from 8 weeks for glecaprevir/pibrentasvir in noncirrhotic treatment-naive patients to 12 weeks for patients with liver cirrhosis or 16 weeks for GT 3 patients with liver cirrhosis and/or prior treatment failure. Sofosbuvir/velpatasvir has to be administered for 12 weeks independently of fibrosis level [3]. Treatment with grazoprevir/elbasvir is possible in patients with GT 1 or 4 infection and has to be administered for 12-16 weeks depending on GT, fibrosis stage and viral load [3].

In most of the cases treatment is well tolerated, and the coadministration of RBV is not necessary. One exception are patients with decompensated liver cirrhosis. These patients benefit from RBV treatment, and higher SVR rates are achieved in particular in those infected with GT $3[3,14]$. 
Table 1. Treatment of patients with chronic hepatitis $C$ without cirrhosis (adapted from Pawlotsky et al. [3] and Mauss et al. [70])

\begin{tabular}{|c|c|c|c|c|c|c|}
\hline GT & Pretreatment & $\begin{array}{l}\text { SOF/LDV, } \\
\text { weeks }\end{array}$ & $\begin{array}{l}\text { GZR/ELB, } \\
\text { weeks }\end{array}$ & $\begin{array}{l}\text { GLE/PIB, } \\
\text { weeks }\end{array}$ & $\begin{array}{l}\text { SOF/VEL, } \\
\text { weeks }\end{array}$ & $\begin{array}{l}\text { SOF/VEL/VOX, } \\
\text { weeks }\end{array}$ \\
\hline \multirow[t]{3}{*}{$1 \mathrm{a}$} & No (naive) & $8^{6}$ & $12^{2}$ & 8 & 12 & $8^{5}$ \\
\hline & IFN/RBV/SOF & $12^{3,5}$ & $12^{2,3}$ & $8^{8}$ & $12^{3}$ & $8^{9}-12^{5}$ \\
\hline & DAA with NS5A inhibitor & No & No & $16^{7}$ & No & 12 \\
\hline \multirow[t]{3}{*}{$1 b$} & No (naive) & $8^{6}$ & $12^{4}$ & 8 & 12 & $8^{5}$ \\
\hline & IFN/RBV/SOF & $12^{3}$ & $12^{3}$ & $8^{8}$ & $12^{3}$ & $8^{9}-12^{5}$ \\
\hline & DAA with NS5A inhibitor & No & No & $16^{7}$ & No & 12 \\
\hline \multirow[t]{3}{*}{2} & No (naive) & No & No & 8 & 12 & $8^{5}$ \\
\hline & IFN/RBV/SOF & No & No & 8 & 12 & $8^{9}-12^{5}$ \\
\hline & DAA with NS5A inhibitor & No & No & No & No & 12 \\
\hline \multirow[t]{3}{*}{3} & No (naive) & No & No & 8 & 12 & $8^{5}$ \\
\hline & IFN/RBV/SOF & No & No & $16^{1}$ & 12 & $8^{9}-12^{5}$ \\
\hline & DAA with NS5A inhibitor & No & No & No & No & 12 \\
\hline \multirow[t]{3}{*}{4} & No (naive) & 12 & $12^{2}$ & 8 & 12 & $8^{5}$ \\
\hline & IFN/RBV/SOF & $12^{3,5}$ & $12^{2,3,5}$ & 8 & $12^{3}$ & $8^{9}-12^{5}$ \\
\hline & DAA with NS5A inhibitor & No & No & No & No & 12 \\
\hline \multirow[t]{3}{*}{5,6} & No (naive) & 12 & No & 8 & 12 & $8^{5}$ \\
\hline & IFN/RBV/SOF & No & No & 8 & 12 & $8^{9}-12^{5}$ \\
\hline & DAA with NS5A inhibitor & No & No & No & No & 12 \\
\hline
\end{tabular}

ELB, elbasvir; GLE, glecaprevir; GZR, grazoprevir; LDV, ledipasvir; IFN, pegylated interferon- $\alpha$; PIB, pibrentasvir; RBV, ribavirin; SOF, sofosbuvir; VEL, velpatasvir; VOX, voxilaprevir; DAA, direct-acting antiviral. ${ }^{1}$ EASL recommends 12 weeks. ${ }^{2} \mathrm{HCV}$-RNA $<800,000$ $\mathrm{IU} / \mathrm{mL}$ at baseline and exclusion of NS5A RAS. ${ }^{3}$ Including treatment experience with IFN + RBV + protease inhibitor (simeprevir, telaprevir or boceprevir). ${ }^{4} 8$ weeks if F0-F2 fibrosis stage. ${ }^{5}$ Not recommended by EASL. ${ }^{6}$ Patients with HCV-RNA $<6$ million IU/mL at baseline. ${ }^{7}$ Prior therapy with NS5A inhibitor but without protease inhibitor (FDA label, not recommended by EMA). ${ }^{8} 12$ weeks if pretreatment with protease inhibitor but without NS5A inhibitor (FDA label, not recommended by EMA). ${ }^{9}$ DAA-naive patients.

Table 2. Treatment of patients with chronic hepatitis $\mathrm{C}$ with compensated cirrhosis (adapted from Pawlotsky et al. [3] and Mauss et al. [70])

\begin{tabular}{|c|c|c|c|c|c|c|}
\hline GT & Pretreatment & $\begin{array}{l}\text { SOF/LDV, } \\
\text { weeks }\end{array}$ & $\begin{array}{l}\text { GZR/ELB, } \\
\text { weeks }\end{array}$ & $\begin{array}{l}\text { GLE/PIB, } \\
\text { weeks }\end{array}$ & $\begin{array}{l}\text { SOF/VEL, } \\
\text { weeks }\end{array}$ & $\begin{array}{l}\text { SOF/VEL/VOX, } \\
\text { weeks }\end{array}$ \\
\hline \multirow[t]{3}{*}{ 1a } & No (naive) & $12^{5}$ & $12^{1}$ & 12 & 12 & $12^{3}$ \\
\hline & IFN/RBV/SOF & $12^{3,5}$ & $12^{1,2}$ & $12^{7}$ & $12^{2}$ & $12^{3}$ \\
\hline & DAA with NS5A inhibitor & No & No & $16^{6}$ & No & 12 \\
\hline \multirow[t]{3}{*}{$1 b$} & No (naive) & $12^{5}$ & 12 & 12 & 12 & $12^{3}$ \\
\hline & IFN/RBV/SOF & $12^{5}$ & $12^{2}$ & $12^{7}$ & $12^{2}$ & $12^{3}$ \\
\hline & DAA with NS5A inhibitor & No & No & $16^{6}$ & No & 12 \\
\hline \multirow[t]{3}{*}{2} & No (naive) & No & No & 12 & 12 & $12^{3}$ \\
\hline & IFN/RBV/SOF & No & No & 12 & 12 & $12^{3}$ \\
\hline & DAA with NS5A inhibitor & No & No & No & No & 12 \\
\hline \multirow[t]{3}{*}{3} & No (naive) & No & No & 12 & $12^{3,4}$ & $8^{8}$ \\
\hline & IFN/RBV/SOF & No & No & 16 & $12^{3,4}$ & 12 \\
\hline & DAA with NS5A inhibitor & No & No & No & No & 12 \\
\hline \multirow[t]{3}{*}{4} & No (naive) & 12 & $12^{1}$ & 12 & 12 & $12^{3}$ \\
\hline & IFN/RBV/SOF & $12^{3,5}$ & $12^{1,2,3}$ & 12 & $12^{2}$ & $12^{3}$ \\
\hline & DAA with NS5A inhibitor & No & No & No & No & 12 \\
\hline \multirow[t]{3}{*}{5,6} & No (naive) & 12 & No & 12 & 12 & $12^{3}$ \\
\hline & IFN/RBV/SOF & No & No & 12 & 12 & $12^{3}$ \\
\hline & DAA with NS5A inhibitor & No & No & No & No & 12 \\
\hline
\end{tabular}

ELB, elbasvir; GLE, glecaprevir; GZR, grazoprevir; LDV, ledipasvir; IFN, pegylated interferon- $\alpha$; PIB, pibrentasvir; RBV, ribavirin; SOF, sofosbuvir; VEL, velpatasvir; VOX, voxilaprevir. ${ }^{1} \mathrm{HCV}-\mathrm{RNA} \leq 800,000 \mathrm{IU} / \mathrm{mL}$ at baseline and exclusion of NS5A RAS. ${ }^{2}$ Including treatment experience with IFN + RBV + protease inhibitor (simeprevir, telaprevir or boceprevir). ${ }^{3}$ Not recommended by EASL. ${ }^{4}$ If NS5A RAS (Y93H) detected additional RBV recommended. ${ }^{5}$ If platelets $<75,000 / \mu \mathrm{L}$ RBV should be added or/and treatment may be extended to 24 weeks. ${ }^{6}$ Prior therapy with NS5A inhibitor but without protease inhibitor (FDA label, not recommended by EMA). ${ }^{7}$ Pretreatment with protease inhibitor but without NS5A inhibitor (FDA label, not recommended by EMA). ${ }^{8}$ EASL recommends 12 weeks. 


\section{Special Groups of Patients}

\section{Treatment of Patients with Prior DAA Treatment Failure}

After failure of DAA treatment, the development of RAS is very likely. RAS linked to the NS5A gene are more likely to persist for a longer time at a significant level than those connected to the NS3/4 gene. RAS relevant for the NS5B inhibitor sofosbuvir are usually rapidly suppressed after treatment cessation due to a significantly impaired viral fitness. Resistance testing and the adaptation of antiviral regimes according to RAS is one possible option for retreatment $[15,16]$. Currently, the only approved drug combination for the retreatment of patients with prior DAA failure is the combination of sofosbuvir, velpatasvir and voxilaprevir (SOF/VEL/VOX) [3]. This combination is not only well tolerated, but also highly effective, and SVR rates $>95 \%$ can be achieved in pretreated patients independently from the initial treatment regimen [17]. The recommended treatment duration for DAA-experienced patients is 12 weeks $[3,18]$. Preliminary real-world data confirmed the high efficacy of the SOF/VEL/VOX in previous DAA failures. All of the first 110 patients who had completed SOF/VEL/VOX in the German Hepatitis C Registry achieved SVR [19]. Excellent results have also been reported from French and US cohorts [20,21]. Due to its effectiveness this combination should be reserved for the retreatment of patients with prior DAA failure and is usually not recommended for the initial treatment of therapy-naive patients [18].

However, not all patients with failure of a first DAA therapy have to be treated with SOF/VEL/VOX. Patients with GT 1 infection and previous antiviral treatment that only included a first-generation protease inhibitor are well eligible for treatment with sofosbuvir/ledipasvir, grazoprevir/elbasvir or sofosbuvir/velpatasvir. Furthermore, the retreatment with glecaprevir/pibrentasvir for 12 or 16 weeks (patients with liver cirrhosis) is possible but currently not approved by the EMA label [22]. Finally, the "off-label" combination of sofosbuvir, glecaprevir/ pibrentasvir and RBV was evaluated in the MAGELLAN-3 study for patients who failed prior therapy with glecaprevir/pibrentasvir [23]. Only 1 patient of 23 experienced viral relapse after 12 or 16 weeks of treatment.

\section{Treatment of Patients with Impaired Renal Function/} Dialysis

Renal excretion is the main elimination pathway of the NS5B polymerase inhibitor sofosbuvir and its metabolites. For patients with mild to moderate renal impairment administration of sofosbuvir is safe. Since patients with severe renal dysfunction or hemodialysis have not been included during the initial phase III study trials, drug safety of sofosbuvir in these patients has not been studied in detail, and therefore sofosbuvir treatment is not recommended by the FDA and EMA label. Nevertheless, some real-world studies and preliminary data of a prospective multicenter trial show high efficacy and safety during full dose sofosbuvir treatment for patients with severe kidney dysfunc nt-related discontinuations or treatment-related serious adverse events [24-26]. However, in some studies these patients also experience higher rates of anemia and worsening of kidney dysfunction [27]. Therefore, sofosbuvir-free treatment options should be preferred if possible. Since the introduction of the pangenotypic combination of glecaprevir/pibrentasvir, a highly effective treatment of GT 2 and 3 is available, and safety and efficacy for patients with renal impairment and hemodialysis have been shown successfully [28]. Alternatively, grazoprevir/elbasvir can be safely administered in patients with GT 1 or 4 infection and severe renal dysfunction [29].

\section{Treatment of Patients with Decompensated Cirrhosis}

Treatment of patients with decompensated cirrhosis (Child-Pugh Score B/C (CPS B/C)) is limited to regimens containing sofosbuvir and NS5A inhibitors. Protease inhibitors are not recommended due to the hepatic metabolization and subsequently significantly higher drug exposure in this group of patients. Thus, grazoprevir/elbasvir, glecaprevir/pibrentasvir or SOF/VEL/VOX should not be administered. To improve efficacy the remaining combination of sofosbuvir and NS5A inhibitor should be combined with RBV [3]. Many studies and real-world data have shown that IFN-free antiviral therapy is safe in patients with advanced liver disease. However, patients are still at risk of hospitalization during therapy, mainly because of complications from liver disease [30-32]. The efficacy of sofosbuvir/ledipasvir plus RBV was studied in the SOLAR-1 and -2 study. In GT 1 patients, SVR rates ranged between 87 and $96 \%$ and between 72 and $85 \%$ in CPS B and CPS C patients, respectively $[31,33]$. The ASTRAL-4 study evaluated the use of sofosbuvir/velpatasvir in patients with CPS B, but not CPS C. Treatment duration of 12 weeks showed high rates of SVR for patients with GT 1, 2, 4 and 6 infection. SVR rates of GT 3 were low at $50 \%$ but could be increased to $85 \%$ by the addition of RBV [14]. Even though the rate of treatment discontinuations is higher in patients treated with RBV, the additional antiviral substance significantly increases SVR rates [3].

Patients with not only decompensated liver cirrhosis, but also additional kidney dysfunction, prior DAA treatment failure or GT 3 infection are especially difficult to treat and should be referred to specialized centers since the administration of sofosbuvir has not been extensively studied in these groups of patients. Similarly, antiviral treatment in patients awaiting liver transplantation should be discussed with the responsible transplantation 
unit. Advantages of viral eradication with improvement of liver function and the prevention of reinfection of the graft have to be outweighed against potential risks of antiviral treatment in patients with decompensated cirrhosis [34]. Generally antiviral treatment after liver transplantation is safe and effective and could also be deferred to the post-transplantation setting. The current IDSA/ AASLD guideline recommends treatment prior to liver transplantation in individuals with a MELD (model of end-stage liver disease) up to 20, while the current EASL guideline is slightly more conservative suggesting a cutoff at $18-20$ MELD points $[3,18]$.

Basically, feasibility of antiviral treatment in liver transplantation candidates should be discussed with the responsible transplantation unit based on the individual health status of the patient and local chances of transplantation.

\section{DAA Treatment and Hepatocellular Carcinoma}

The impact of DAA treatment on hepatocellular carcinoma (HCC) incidence, recurrence and tumor aggressiveness in patients with chronic HCV infection has been intensively discussed over the last 2 years. Shortly after DAA approval, an observed increase in early occurrence or recurrence of HCC after HCV eradication with DAA has been reported $[35,36]$.

However, the higher incidence of de novo HCC compared to historical data was most likely related to a significantly higher proportion of older patients as well as those with end-stage liver disease certainly ineligible for IFN-based regimens. Later on, further data analysis revealed that $\mathrm{HCV}$ eradication due to DAA treatment reduces the risk of HCC development to a comparable lev$\mathrm{el}$ as with IFN-based therapies [37]. These findings were supported by results from prospective studies showing a reduction of HCC incidence in patients with HCV-related liver cirrhosis [38]. Nevertheless, the absolute risk of HCC development remains high in patients with established cirrhosis. Ongoing HCC surveillance is mandatory despite HCV clearance [39].

In contrast, the impact of DAA treatment on HCC recurrence might be more controversial [40]. However, it has to be noted that the majority of HCC recurrences during DAA therapy occurred within the first 6 months after HCC treatment. Furthermore, according to a retrospective study from North America and a prospective study from Italy, HCC recurrence rates were similar between DAA and non-DAA treatment in patients with liver cirrhosis and curative oncological treatment prior to antiviral treatment. Patients treated with DAA showed improved overall survival and a reduced risk of hepatic decompensation [41, 42]. In our opinion, patients with HCV cirrhosis who have undergone definite HCC treatment with confirmed success 6 months after should not be excluded from DAA treatment to prevent the progression of liver disease.

\section{Treatment after Liver Transplantation}

After liver transplantation reinfection of the graft leads to fast development of liver fibrosis, and consequently the risks of organ dysfunction and graft loss are significantly increased $[43,44]$. Thus, antiviral treatment is essential to preserve liver function and ensure transplant survival [45]. Severe post-transplantation cholestatic hepatitis and patients with moderate to severe fibrosis need urgent initiation of antiviral treatment to prevent graft loss $[44,46]$. In the SOLAR-1 and -2 trials patients after liver transplantation show similar SVR rates compared to nontransplanted patients with the treatment of sofosbuvir/ledipasvir plus RBV $[31,33]$. Comparable results were achieved by the combination of sofosbuvir/velpatasvir [47]. These results are supported by data from several real-world studies confirming the efficacy and safety of DAA treatment in the post-transplantation setting. Potential DDI between DAA and immunosuppressive drugs require special attention, in particular when using protease inhibitors. However, the combination of glecaprevir/pibrentasvir is certainly a valuable pangenotypic alternative to sofosbuvir-containing regimens, in particular for patients with impaired kidney function after liver transplantation [48]. During DAA treatment serum levels of immunosuppressant drugs have to be closely monitored.

\section{Treatment of Patients with Co-Infection}

In patients with hepatitis $B$ virus (HBV) co-infection, HBV DNA is usually low although fluctuation cannot be excluded whereas HCV RNA is present and the driver of hepatic inflammation. Before antiviral treatment the replicative virus status including hepatitis delta has to be determined. In case of present HCV RNA, antiviral treatment against HCV should be initiated following the same recommendations as for monoinfected patients [3]. SVR rates of $\mathrm{HCV}$ therapy are not impaired by $\mathrm{HBV}$ co-infection or HBV treatment and, although tenofovir displays potential DDI with DAA, the administration of entecavir is uncomplicated $[49,50]$. Some studies report an increase in HBV DNA levels or HBV reactivation during $\mathrm{HCV}$ antiviral treatment but so far, the risk of reactivation and possible clinical deterioration are unpredictable [51-53]. Current guidelines recommend initiation of concomitant antiviral HBV treatment in patients with positive $\mathrm{HBs}$ antigen. In case of negative $\mathrm{HBs}$ antigen but anti-HBc-positive antibodies, alanine transaminase (ALT) levels should be monitored irrelevant of anti-HBs antibody status. If ALT levels do not normalize or rise during DAA therapy and HBs antigen or HBV DNA are detectable, HBV treatment should be initiated [3]. 
Table 3. Induction and inhibition of enzymes or transporters by active substances for HCV therapy

\begin{tabular}{|c|c|c|c|c|}
\hline & \multicolumn{4}{|l|}{$\uparrow$ Induction / inhibition $\downarrow$ (details) } \\
\hline & $\mathrm{CYP}$ & P-gp & OATP & BCRP \\
\hline Daclatasvir & $\uparrow(3 \mathrm{~A} 4$, weak $)$ & $\downarrow$ (cave: narrow TR) & $\downarrow(1 \mathrm{~B} 1)$ & $\downarrow$ \\
\hline Simeprevir & $\downarrow$ (1A2, intestinal 3A4; both weak) & $\downarrow$ & $\downarrow(1 \mathrm{~B} 1 / 3)$ & $\downarrow$ \\
\hline Sofosbuvir & no interaction expected & no interaction expected & no interaction expected & $\begin{array}{l}\text { no interaction } \\
\text { expected }\end{array}$ \\
\hline Ribavirin & no interaction expected & no interaction expected & no interaction expected & $\begin{array}{l}\text { no interaction } \\
\text { expected }\end{array}$ \\
\hline SOF/LDV & no interaction expected & $\downarrow$ (in vitro) & $\downarrow$ (possible) & $\downarrow$ (in vitro) \\
\hline GZR/ELB & $\downarrow$ (3A, weak, in vivo) & $\downarrow$ (weak, intestinal, in vivo) & no interaction expected & $\downarrow$ (intestinal) \\
\hline GLE/PIB & $\downarrow(3 \mathrm{~A}$, weak, in vivo $)$ & $\downarrow$ & $\downarrow(1 \mathrm{~B} 1 / 3)$ & $\downarrow$ \\
\hline SOF/VEL & no interaction expected & $\downarrow$ (in vitro) & $\downarrow(1 \mathrm{~B}$, in vitro $)$ & $\downarrow$ (in vitro) \\
\hline SOF/VEL/VOX & no interaction expected & $\downarrow$ (in vitro) & $\downarrow(1 \mathrm{~B}$, in vitro $)$ & $\downarrow$ (in vitro) \\
\hline Substrates & $\begin{array}{l}\text { 1A2: theophylline } 3 \mathrm{~A} 4 \text { : } \\
\text { cyclosporine }\end{array}$ & $\begin{array}{l}\text { dabigatran, digoxin, } \\
\text { carvedilol }\end{array}$ & $\begin{array}{l}\text { 1B: simvastatin, } \\
\text { atorvastatin }\end{array}$ & $\begin{array}{l}\text { simvastatin, } \\
\text { atorvastatin }\end{array}$ \\
\hline
\end{tabular}

SOF, sofosbuvir; LDV, ledipasvir; GZR, grazoprevir; ELB, elbasvir; GLE, glecaprevir; PIB, pibrentasvir; VEL, velpatasvir; VOX, voxilaprevir; CYP, cytochrome P-450 enzyme; P-gp, permeability glycoprotein; OATP, organic anion-transporting polypeptide; BCRP, breast cancer resistance protein; $\mathrm{TR}$, therapeutic range.

Treatment recommendations for patients with HCV/ $\mathrm{HIV}$ co-infection do not differ from $\mathrm{HCV}$-monoinfected patients. Potential DDI between antiretroviral drugs and DAA have to be taken into account before choosing a DAA regimen, especially if NS3/4 protease inhibitors are included $[3,18]$.

\section{Side Effects}

Former antiviral regimens containing protease inhibitors like boceprevir or telaprevir combined with peginterferon alfa had serious side effects $[54,55]$. When looking at more modern regimens like glecaprevir/pibrentasvir, elbasvir/grazoprevir and velpatasvir/sofosbuvir \pm voxilaprevir, the potential for side effects does not seem to turn the balance in HCV therapy anymore. All substances are mostly well tolerated. The most important side effects are headache, fatigue, nausea and diarrhea and occur in $\geq 1 / 10$ patients. Additionally, the possible increases in ALT levels and bilirubin are important and need to be monitored during therapy. Anyhow less than $1 \%$ of patients have to discontinue therapy due to side effects [56-59]. Ribavirin, still being a treatment option in some cases, causes hemolytic anemia in $\geq 1 / 10$ patients [60]. This can result in dose reductions or even discontinuation of RBV treatment. When using RBV in HCV/HIV co-infected patients, a possible mitochondrial toxicity and lactate acidosis need to be kept in mind. Due to the fact that records of possible side effects of RBV were often conducted in combination with peginterferon, interpretation as RBV specific side effects should always be made with caution [61].

\section{DDI as Complication in HCV Therapy}

On the one hand side effects, not being a major issue in HCV therapy anymore, are a disappearing challenge. On the other hand, DDI have expanded as a new complication when treating with DAA. Several publications over the last few years have pointed out that up to $40 \%$ of $\mathrm{HCV}$ patients might be affected by significant DDI $[13,62]$. DDI can either have pharmacodynamic or pharmacokinetic impact or both on all involved substances. Table 3 summarizes pharmacokinetic information about the active substances for HCV treatment according to the prescribing information (as of May 2019). The classical substrates mentioned in Table 3 are kinetically influenced by concomitant use of DAA, and the risk of adverse events like dose-dependent toxicity, higher bleeding risk, adverse cardiac events or rhabdomyolysis increases. On the basis of these data a prediction of possible DDI can be made. Not only substances for HCV treatment can influence the kinetics of other drugs, this can also occur vice versa. For example, metamizole is a CYP 3A4 inductor and may decrease concentrations of DAA being metabolized via this enzyme [50]. 


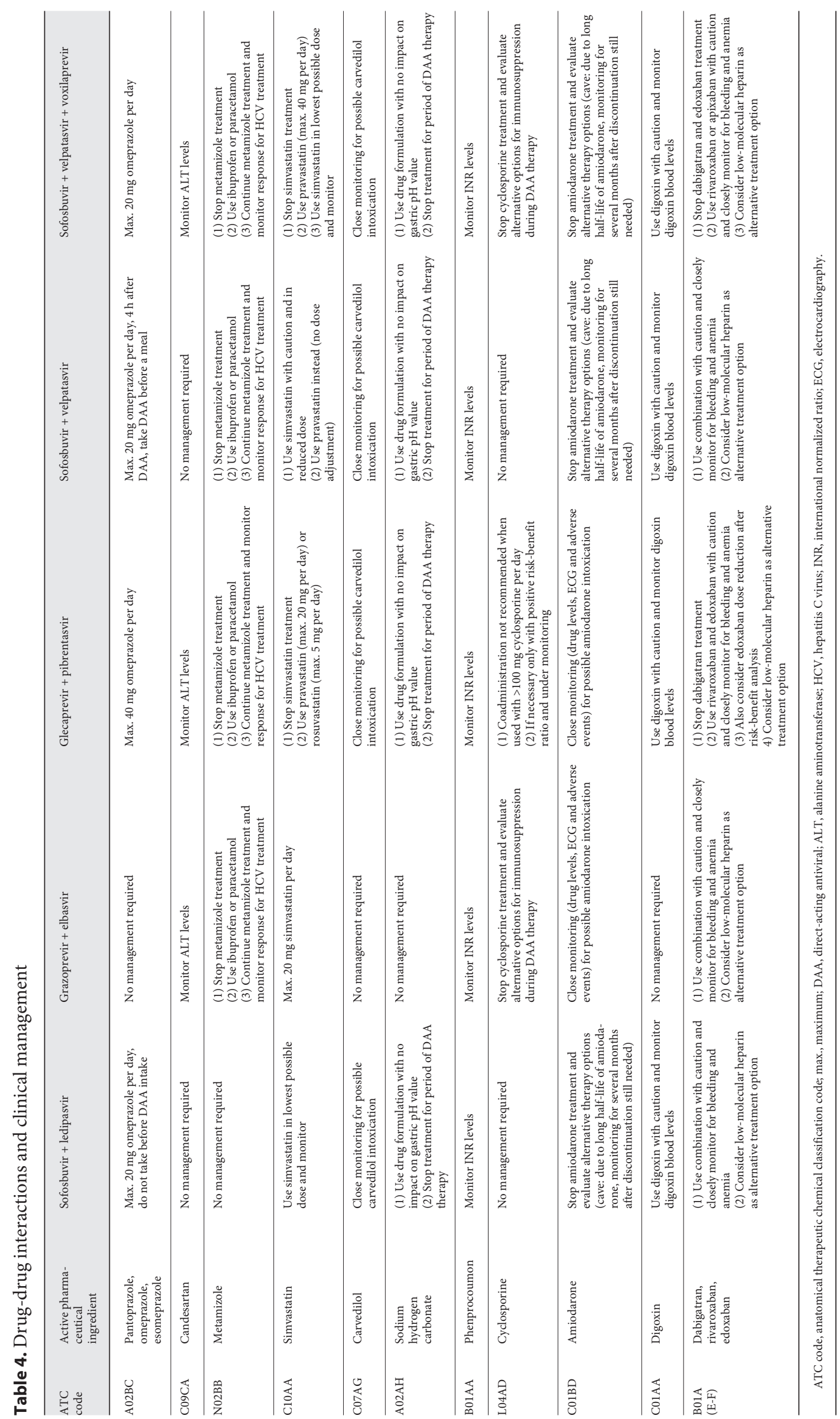


Looking at proton pump inhibitors the increasing $\mathrm{pH}$ value in the stomach under therapy leads to decreased solubility of ledipasvir, glecaprevir and velpatasvir. This causes lower bioavailability and potentially even a higher risk of efficacy loss. The clinical relevance of this interaction seems to be dose dependent $[50,56,63]$. Candesartan is a permeability glycoprotein inhibitor, and concentrations of DAA transported via permeability glycoprotein may be increased. In case of dose dependent ALT elevations closer monitoring may be required [50]. A possible fluctuation of liver function during and after therapy of $\mathrm{HCV}$ patients can cause a change of INR levels when under anticoagulative therapy with phenprocoumon. Patients should be closely monitored during concomitant use [50, 56-59]. The combination of ethinylestradiol with glecaprevir/pibrentasvir and velpatasvir/sofosbuvir + voxilaprevir can lead to ALT elevation and is therefore contraindicated [56, 59]. Last but not least DDI with the following medications need also to be kept in mind when treating with DAA: (1) amiodarone, (2) St. John's wort, (3) rifampicin, (4) antiepileptic drugs, (5) antiretroviral medications and (6) psychotropic drugs [50, 64, 65].

However, theoretical potential for interactions does not always result in clinically relevant DDI. When predicting clinically relevant DDI, the following point needs to be kept in mind. DDI studies with reliable clinical end points or pharmacokinetic data are most eligible to determine clinical significance but still need an expert for interpretation, and in most cases such studies are not available [66]. Table 4 shows commonly used concomitant medications in HCV, clinically relevant DDI with modern HCV regimens and the suggested management based on prescription information (as of May 2019), www.hep-druginteractions.org (as of May 2019) and authors' expertise [67].

\section{Conclusion and Remaining Challenges}

With the availability of DAA, high rates of viral eradication can be realized while treatment is overall safe. DDI need to be considered but are well manageable. Given that antiviral treatment is highly effective, treatment accessibility seems to be the current limitation of $\mathrm{HCV}$ eradication. Screening of patients has to be improved for the identification of infected patients prior to the development of liver disease. Especially in high-risk populations (intravenous drug users, prison inmates, men who have sex with men), infected patients have to be identified and importantly need to be treated to limit viral spreading. Therefore, barriers to treatment access like e.g. treatment pricing or medical infrastructure have to be addressed to allow treatment of the "unreached" patients [68]. To ensure the sustainability of antiviral treatment, prevention activities have to be implemented and improved and might even include the development of an $\mathrm{HCV}$ vaccine which is not available yet.

\section{Statement of Ethics}

The authors have no ethical conflicts to disclose.

\section{Disclosure Statement}

L.S. and B.S. have no conflict of interest to declare. M.P.M. received speaker and/or consulting fees and/or grant/research support from AbbVie, BMS, Gilead, Merck/MSD and Janssen. B.M. received speaker and/or consulting fees from Abbott Molecular, Astellas, Intercept, Falk, AbbVie, Bristol-Myers Squibb, Fujirebio, Janssen-Cilag, Merck/MSD and Roche. He also received research support from Abbott Molecular and Roche.

\section{Funding Source}

To conduct this research no funding was received.

\section{Author Contributions} B.M.

\section{References}

1 WHO. Global hepatitis report, 2017 [Internet]. World Health Organisation. 2017. Available from: http://www.who.int/hepatitis

2 Maasoumy B, Wedemeyer H. Natural history of acute and chronic hepatitis C. Best Pract Res Clin Gastroenterol. 2012 Aug;26(4):40112.

3 Pawlotsky JM, Negro F, Aghemo A, Berenguer M, Dalgard O, Dusheiko G, et al.; European Association for the Study of the Liver.
Electronic address: easloffice@easloffice.eu; European Association for the Study of the Liver. EASL Recommendations on Treatment of Hepatitis C 2018. J Hepatol. 2018 Aug; 69(2):461-511.

4 van der Meer AJ, Wedemeyer H, Feld JJ, Dufour JF, Zeuzem S, Hansen BE, et al. Life expectancy in patients with chronic $\mathrm{HCV}$ infection and cirrhosis compared with a general population. JAMA. 2014 Nov;312(18): 1927-8.
5 Pascasio JM, Vinaixa C, Ferrer MT, Colmenero J, Rubin A, Castells L, et al. Clinical outcomes of patients undergoing antiviral therapy while awaiting liver transplantation. J Hepatol. 2017 Dec;67(6):1168-76.

6 Carrat F, Fontaine H, Dorival C, Simony M, Diallo A, Hezode C, et al.; French ANRS CO $22 \mathrm{He}$ pather cohort. Clinical outcomes in patients with chronic hepatitis $\mathrm{C}$ after direct-acting antiviral treatment: a prospective cohort study [Internet]. Lancet. 2019 Apr;393(10179):1453-64. 
7 Younossi Z, Henry L. Systematic review: patient-reported outcomes in chronic hepatitis $\mathrm{C}$ - the impact of liver disease and new treatment regimens. Aliment Pharmacol Ther. 2015 Mar;41(6):497-520.

8 Cheung MC, Walker AJ, Hudson BE, Verma S, McLauchlan J, Mutimer DJ, et al.; HCV Research UK. Outcomes after successful directacting antiviral therapy for patients with chronic hepatitis $\mathrm{C}$ and decompensated cirrhosis. J Hepatol. 2016 Oct;65(4):741-7.

9 Höner Zu Siederdissen C, Schlevogt B, Solbach P, Port K, Cornberg M, Manns MP, et al. Real-world effect of ribavirin on quality of life in $\mathrm{HCV}$-infected patients receiving interferon-free treatment. Liver Int. 2018 May;38(5): 834-41.

10 Foster GR, Irving WL, Cheung MC, Walker AJ, Hudson BE, Verma S, et al.; HCV Research, UK. Impact of direct acting antiviral therapy in patients with chronic hepatitis $\mathrm{C}$ and decompensated cirrhosis. J Hepatol. 2016 Jun;64(6):1224-31.

11 van Seyen M, Smolders EJ, van Wijngaarden P, Drenth JP, Wouthuyzen-Bakker M, de Knegt RJ, et al. Successful HCV treatment of patients on contraindicated anti-epileptic drugs: role of drug level monitoring. J Hepatol. 2019 Mar;70(3):552-4.

12 Smolders EJ, Ter Horst PJ, Wolters S, Burger DM. Cardiovascular risk management and hepatitis C: combining drugs [Internet]. Clin Pharmacokinet. 2019 May;58(5):565-92.

13 Höner Zu Siederdissen C, Maasoumy B, Marra F, Deterding $\mathrm{K}$, Port $\mathrm{K}$, Manns $\mathrm{MP}$, et al. Drug-Drug Interactions With Novel All Oral Interferon-Free Antiviral Agents in a Large Real-World Cohort. Clin Infect Dis. 2016 Mar;62(5):561-7.

14 Curry MP, O’Leary JG, Bzowej N, Muir AJ, Korenblat KM, Fenkel JM, et al.; ASTRAL-4 Investigators. Sofosbuvir and Velpatasvir for HCV in Patients with Decompensated Cirrhosis. N Engl J Med. 2015 Dec;373(27):261828.

15 Dietz J, Susser S, Vermehren J, Peiffer KH, Grammatikos G, Berger A, et al.; European HCV Resistance Study Group. Patterns of Resistance-Associated Substitutions in Patients With Chronic HCV Infection Following Treatment With Direct-Acting Antivirals. Gastroenterology. 2018 Mar;154(4):976-988. e4.

16 Sarrazin C. The importance of resistance to direct antiviral drugs in $\mathrm{HCV}$ infection in clinical practice. J Hepatol. 2016 Feb;64(2): 486-504.

17 Bourlière M, Gordon SC, Flamm SL, Cooper CL, Ramji A, Tong M, et al.; POLARIS-1 and POLARIS-4 Investigators. Sofosbuvir, Velpatasvir, and Voxilaprevir for Previously Treated HCV Infection. N Engl J Med. 2017 Jun; 376(22):2134-46

18 AASLD-IDSA. HCV guidance: recommendations for testing, managing, and treating hepatitis C [Internet] [cited 2019 Mar 11]. Available from: https://www.hcvguidelines. org

19 Vermehren J, Stoehr A, Schulze zur Wiesch J, Klinker H, Cornberg M, Jung M-C, et al. Retreatment with sofosbuvir/velpatasvir/ voxilaprevir in patients with chronic hepati- tis $\mathrm{C}$ virus infection and prior DAA failure - an analysis from the German Hepatitis CRegistry (DHC-R). J Hepatol. 2019 Apr; 70(1):e245.

20 Hezode C, Guyader D, Nguyen-Khac E, Larrey D, Truchi R, Di Martino V, et al. Sofosbuvir + velpatasvir + voxilaprevir in DAA failure patients with cirrhosis: Final results of the French compassionate use program. J Hepatol. 2019 Apr;70(1):e224.

21 Bacon B, Curry M, Flamm S, Milligan S, Tsai $\mathrm{N}$, Wick N, et al. Effectiveness of the salvage therapy sofosbuvir-velpatasvir-voxilaprevir (SOF-VEL-VOX) in chronic hepatitis C: clinical practice experience from the TRIO Network. J Hepatol. 2019 Apr;70(1):e209.

22 Poordad F, Pol S, Asatryan A, Buti M, Shaw D, Hézode C, et al. Glecaprevir/Pibrentasvir in patients with hepatitis $\mathrm{C}$ virus genotype 1 or 4 and past direct-acting antiviral treatment failure. Hepatology. 2018 Apr;67(4):1253-60.

23 Wyles D, Weiland O, Yao B, Reindollar R, Weilert F, Dufour JF, et al. Retreatment of patients who failed glecaprevir/pibrentasvir treatment for hepatitis $\mathrm{C}$ virus infection. J Hepatol. 2018 Apr;68:S23-4.

24 Desnoyer A, Pospai D, Lê MP, Gervais A, Heurgué-Berlot A, Laradi A, et al. Pharmacokinetics, safety and efficacy of a full dose sofosbuvir-based regimen given daily in hemodialysis patients with chronic hepatitis C. J Hepatol. 2016 Jul;65(1):40-7.

25 Manoj Kumar, Nayak SL, Gupta E, Kataria A, Sarin SK. Generic sofosbuvir-based directacting antivirals in hepatitis $\mathrm{C}$ virus-infected patients with chronic kidney disease. Liver Int. 2018 Dec;38(12):2137-48.

26 Borgia SM, Dearden J, Lurie Y, Shafran SD, Brown A, Hyland RH, et al. Sofosbuvir/velpatasvir for 12 weeks is safe and effective in patients undergoing dialysis. AASLD 2018 Nov 9-13, San Francisco.

27 Saxena V, Koraishy FM, Sise ME, Lim JK, Schmidt M, Chung RT, et al.; HCV-TARGET. Safety and efficacy of sofosbuvir-containing regimens in hepatitis $\mathrm{C}$-infected patients with impaired renal function. Liver Int. 2016 Jun; 36(6):807-16.

28 Gane E, Lawitz E, Pugatch D, Papatheodoridis G, Bräu N, Brown A, et al. Glecaprevir and pibrentasvir in patients with $\mathrm{HCV}$ and severe renal impairment. N Engl J Med. 2017 Oct; 377(15):1448-55.

29 Roth D, Nelson DR, Bruchfeld A, Liapakis A, Silva M, Monsour H Jr, et al. Grazoprevir plus elbasvir in treatment-naive and treatment-experienced patients with hepatitis $\mathrm{C}$ virus genotype 1 infection and stage 4-5 chronic kidney disease (the C-SURFER study): a combination phase 3 study. Lancet. 2015 Oct; 386(10003):1537-45.

30 Welker MW, Luhne S, Lange CM, Vermehren J, Farnik H, Herrmann E, et al. Lactic acidosis in patients with hepatitis $\mathrm{C}$ virus cirrhosis and combined ribavirin/sofosbuvir treatment. J Hepatol. 2016 Apr;64(4):790-9.

31 Manns M, Samuel D, Gane EJ, Mutimer D, McCaughan G, Buti M, et al.; SOLAR-2 investigators. Ledipasvir and sofosbuvir plus ribavirin in patients with genotype 1 or 4 hepatitis $\mathrm{C}$ virus infection and advanced liver disease: a multicentre, open-label, randomised, phase
2 trial. Lancet Infect Dis. 2016 Jun;16(6):68597.

32 Höner Zu Siederdissen C, Maasoumy B, De terding K, Port K, Sollik L, Mix C, et al. Eligibility and safety of the first interferon-free therapy against hepatitis $\mathrm{C}$ in a real-world setting. Liver Int. 2015 Jul;35(7):1845-52.

33 Charlton M, Everson GT, Flamm SL, Kumar P, Landis C, Brown RS Jr, et al.; SOLAR-1 Investigators. Ledipasvir and Sofosbuvir Plus Ribavirin for Treatment of HCV Infection in Patients With Advanced Liver Disease. Gastroenterology. 2015 Sep;149(3):649-59.

34 Sandmann L, Dörge P, Wranke A, Vermehren J, Welzel TM, Berg CP, et al. Treatment strategies for patients with decompensated liver cirrhosis due to hepatitis $\mathrm{C}$ virus infection eligible for liver transplantation: real-life data from five German transplant centers. Eur J Gastroenterol Hepatol. 2019 Feb;1.

35 Kozbial K, Moser S, Schwarzer R, Laferl H, Al-Zoairy R, Stauber R, et al. Unexpected high incidence of hepatocellular carcinoma in cirrhotic patients with sustained virologic response following interferon-free direct-acting antiviral treatment. J Hepatol. 2016;65:856-8.

36 Reig M, Mariño Z, Perelló C, Iñarrairaegui M, Ribeiro A, Lens S, et al. Unexpected high rate of early tumor recurrence in patients with HCV-related HCC undergoing interferonfree therapy. J Hepatol. 2016 Oct;65(4):71926.

37 Kobayashi M, Suzuki F, Fujiyama S, Kawamura Y, Sezaki H, Hosaka T, et al. Sustained virologic response by direct antiviral agents reduces the incidence of hepatocellular carcinoma in patients with $\mathrm{HCV}$ infection. J Med Virol. 2017 Mar;89(3):476-83.

38 Calvaruso V, Cabibbo G, Cacciola I, Petta S, Madonia S, Bellia A, et al.; Rete Sicilia Selezione Terapia-HCV (RESIST-HCV). Incidence of Hepatocellular Carcinoma in $\mathrm{Pa}$ tients With HCV-Associated Cirrhosis Treated With Direct-Acting Antiviral Agents. Gastroenterology. 2018 Aug;155(2):411-421. e4.

39 Kanwal F, Kramer J, Asch SM, Chayanupatkul M, Cao Y, El-Serag HB. Risk of Hepatocellular Cancer in HCV Patients Treated With Direct-Acting Antiviral Agents. Gastroenterology. 2017 Oct;153(4):996-1005.e1.

40 Waziry R, Hajarizadeh B, Grebely J, Amin J, Law M, Danta M, et al. Hepatocellular carcinoma risk following direct-acting antiviral HCV therapy: A systematic review, metaanalyses, and meta-regression. J Hepatol. 2017 Dec;67(6):1204-12.

41 Singal AG, Rich NE, Mehta N, Branch A, Pillai A, Hoteit M, et al. Direct-Acting Antiviral Therapy Not Associated With Recurrence of Hepatocellular Carcinoma in a Multicenter North American Cohort Study. Gastroenterology. 2019 May;156(6):1683-1692.e1.

42 Cabibbo G, Celsa C, Calvaruso V, Petta S, Cacciola I, Cannavò MR, et al.; Rete Sicilia Selezione Terapia - HCV (RESIST-HCV), Italian Liver Cancer (ITA.LI.CA.) Group. Direct acting antivirals after successful treatment of early hepatocellular carcinoma improve survival in $\mathrm{HCV}$-cirrhotic patients. J Hepatol. 2019;S0168-8278(19)30221-1. Epub 2019 Apr 5. 
43 Berenguer M. What determines the natural history of recurrent hepatitis $\mathrm{C}$ after liver transplantation? J Hepatol. 2005 Apr;42(4): 448-56.

44 Neumann UP, Berg T, Bahra M, Puhl G, Guckelberger $\mathrm{O}$, Langrehr JM, et al. Long-term outcome of liver transplants for chronic hepatitis C: a 10-year follow-up. Transplantation. 2004 Jan;77(2):226-31.

45 Picciotto FP, Tritto G, Lanza AG, Addario L De Luca M, Di Costanzo GG, et al. Sustained virological response to antiviral therapy reduces mortality in HCV reinfection after liver transplantation. J Hepatol. 2007 Mar;46(3): 459-65.

46 Blasco A, Forns X, Carrión JA, García-Pagán JC, Gilabert R, Rimola A, et al. Hepatic venous pressure gradient identifies patients at risk of severe hepatitis $\mathrm{C}$ recurrence after liver transplantation. Hepatology. 2006 Mar;43(3): 492-9.

47 Agarwal K, Castells L, Müllhaupt B, Rosenberg WM, McNabb B, Arterburn S, et al. Sofosbuvir/velpatasvir for 12 weeks in genotype 1-4 HCV-infected liver transplant recipients. J Hepatol. 2018 Sep;69(3):603-7.

48 Reau N, Kwo PY, Rhee S, Brown RS Jr, Agarwal K, Angus P, et al. Glecaprevir/Pibrentasvir Treatment in Liver or Kidney Transplant Patients With Hepatitis C Virus Infection. Hepatology. 2018 Oct;68(4):1298-307.

49 Gane EJ, Hyland RH, An D, Svarovskaia ES, Brainard D, McHutchison JG. Ledipasvir and sofosbuvir for $\mathrm{HCV}$ infection in patients coinfected with HBV. Antivir Ther. 2016, 21(7):605-9.

50 University of Liverpool. https://www.hepdruginteractions.org [Internet] [cited 2019 Mar 9]. Available from: https://www.hepdruginteractions.org

51 Potthoff A, Berg T, Wedemeyer H; HEP-NET B/C Coinfection Study Group. Late hepatitis $B$ virus relapse in patients co-infected with hepatitis B virus and hepatitis C virus after antiviral treatment with pegylated interferon$\mathrm{a} 2 \mathrm{~b}$ and ribavirin. Scand J Gastroenterol. 2009;44(12):1487-90.

52 Wang C, Ji D, Chen J, Shao Q, Li B, Liu J, et al. Hepatitis due to Reactivation of Hepatitis B Virus in Endemic Areas Among Patients With Hepatitis C Treated With Direct-acting Antiviral Agents. Clin Gastroenterol Hepatol. 2017 Jan;15(1):132-6.

53 Liu CJ, Chuang WL, Sheen IS, Wang HY, Chen CY, Tseng KC, et al. Efficacy of Ledipasvir and Sofosbuvir Treatment of HCV Infection in Patients Coinfected With HBV. Gastroenterology. 2018 Mar;154(4):989-97.

54 Merck Sharp \& Dohme Ltd (MSD). Prescribing information Victrelis(R) 200 mg. 2015 February.

55 Janssen Cilag International NV (Janssen). Prescribing information Incivo(R) $375 \mathrm{mg}$. 2011 September.

56 AbbVie Deutschland GmbH \& Co. KG (Abbvie). Prescribing information Maviret(R) $100 \mathrm{mg} / 40 \mathrm{mg}$. 2018 November.

57 Merck Sharp \& Dohme BV (MSD). Prescribing information Zepatier(R) $50 \mathrm{mg} / 100 \mathrm{mg}$. 2018 December.

58 Gilead Sciences Ireland UC (Gilead). Prescribing information Epclusa(R) 400 mg/100 mg. 2018 June.

59 Gilead Sciences Ireland UC (Gilead). Prescribing information Vosevi $400 \mathrm{mg} / 100$ mg/100 mg. 2019 January.

60 Manns MP, Wedemeyer H, Cornberg M. Treating viral hepatitis C: efficacy, side effects, and complications. Gut. 2006 Sep;55(9): 1350-9.

61 Ratiopharm GmbH (Ratiopharm). Prescribing information Ribavirin-ratiopharm 200 mg/400 mg. 2018 June.

62 Maasoumy B, Port K, Calle Serrano B, Markova AA, Sollik L, Manns MP, et al. The clinical significance of drug-drug interactions in the era of direct-acting anti-viral agents against chronic hepatitis C. Aliment Pharmacol Ther. 2013 Dec;38(11-12):1365-72.

63 Flamm S, Reddy KR, Zadeikis N, Hassanein T, Bacon BR, Maieron A, et al. Efficacy and Pharmacokinetics of Glecaprevir and Pibrentasvir With Concurrent Use of Acid-Reducing Agents in Patients With Chronic HCV Infection. Clin Gastroenterol Hepatol. 2019 Feb;17(3):527-535.e6.

64 Renet S, Chaumais MC, Antonini T, Zhao A Thomas L, Savoure A, et al. Extreme bradycardia after first doses of sofosbuvir and daclatasvir in patients receiving amiodarone: 2 cases including a rechallenge. Gastroenterology. 2015 Nov;149(6):1378-1380.e1.

65 Roncero C, Villegas JL, Martínez-Rebollar M, Buti M. The pharmacological interactions between direct-acting antivirals for the treatment of chronic hepatitis $\mathrm{c}$ and psychotropic drugs. Expert Rev Clin Pharmacol. 2018 Oct; 11(10):999-1030

66 Back D, Else L. The importance of drug-drug interactions in the DAA era. Dig Liver Dis. 2013 Sep;45 Suppl 5:S343-8.

67 Schulte B, Wübbolding M, Port K, Manns MP, Back D, Marra F, et al. Drug-drug interactions in $\mathrm{HCV}$ therapy: still relevant for clinical practice? J Hepatol. 2019 Apr; 70(1):e240.

68 WHO. Combating hepatitis $\mathrm{B}$ and $\mathrm{C}$ to reach elimination by 2030 [Internet]. 2016 [cited 2019 Mar 17]. Available from: https://apps. who.in t/iris/bitstrea m/ h a n dle/10665/206453/WHO_HIV_2016.04_ eng.pdf? sequence $=1$

69 Manns MP, Cornberg M. Sofosbuvir: the final nail in the coffin for hepatitis C? Lancet Infect Dis. 2013 May; 13(5):378-9.

70 Mauss S, Berg T, Rockstroh J, Sarrazin C, Wedemeyer H. Hepatology - a clinical textbook [Internet]. 9th ed. 2018. Available from: www.hepatologytextbook.com 